\title{
Изучение спектров поглощения вин различных типов и возраста в УФ-диапазоне длин волн
}

\author{
Руслан Генрихович Тимофеев, канд. техн. наук, доцент, вед. науч. сотр. лаборатории тихих вин, Russ1970@mail.ru; \\ https://orcid.org/0000-0002-6105-944X; \\ Нина Александровна Фоменко, ведущий инженер-исследователь лаборатории экспериментального виноделия и \\ коллекционных вин \\ Федеральное государственное бюджетное учреждение науки «Всероссийский национальный научно-исследовательский институт \\ виноградарства и виноделия «Магарач» РАН», Россия, Республика Крым, 298600, г. Ялта, ул. Кирова, 31
}

\begin{abstract}
Приведены результаты анализа спектров поглощения вин различных типов и возраста в УФ-диапазоне длин волн. Определены закономерности изменения оптической плотности в УФ-диапазоне длин волн образцов вин в зависимости от их типа и возраста. Показано, что оптическая плотность вин одного возраста на длине волны $280 \mathrm{~nm}$ пропорциональна массовой концентрации суммы фенольных веществ, определенной с реактивом Фолина-Чокальтеу. Введено поня т ие «коэффициента поглощения фенольных веществ винограда и вина». Разработан методологический подход к определению массовой концентрации фенольных веществ в молодых винах.
\end{abstract}

Ключевые слова: виноделие; фенольные вещества; спектрофотометрия; методы контроля.
O R I G I N A L A R T I C L E

\section{The study of the absorption spectra of the wines of different types and ages in the UV range of wavelengths}

\author{
Ruslan Genrihovich Timofeev, Nina Alexandrovna Fomenko \\ Federal State Budget Scientific Institution All-Russian National Research Institute of \\ Viticulture and Winemaking Magarach of RAS, 31 Kirova Street, 298600 Yalta, Republic of \\ Crimea, Russia
}

The paper highlights the results of the absorption spectra analysis of base wines of various types and ages in the UV wavelength range. Patterns have been established for optical density vatriations in the UV wavelength range of base wine samples depending on their type and age. It is shown that the optical density of base wines of the same age at the wavelength of $280 \mathrm{~nm}$ is proportional to the mass concentration of total phenolic substances, determined with Folin-Chocalteu reagent. The concept of "phenolic substances of grapes and wine absorption coefficient" was introduced. A methodological approach was developed to determine mass concentration of phenolic substances in young base wines. Key words: winemaking; phenolic substances; spectrophotometry; control methods.

спектрофотометрических ячеек, сопряженных с блоками обработки Аанных. Точность таких методов может уступать точности аттестованных методик, но достаточна Аля оперативного мониторинга состава вин и принятия решения с целью корректировки технологического процесса. Кроме того, большое развитие получают системы многопараметрического контроля среА, когАа в обработку поступают Аанные по нескольким измеряемым физическим параметрам, а алгоритм обработки данных и показатели состава вычисляются в зависимости от абсолютных значений регистрируемых параметров среды [1].

Известный факт, что фенольные соединения винограда имеют высокий коэффициент погмощения световой энергии в УФ-Аиапазоне

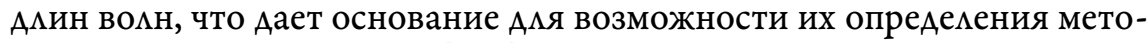
Аами спектрофотометрии [2-5]. УФ-спектр поглощения фцавоноиАов характеризуется, как правимо, двумя максимумами погмощения [6]. Так фмавоны и фцавонолы обычно имеют сильную полосу поглощения при 320-380 nm (полоса I) и при 240-270 nm (полоса II). Положение и интенсивность максимумов поглощения зависят от Аальнейших структурных размичий. Наличие заместителей опреАеляет форму УФспектра погмощения фенольных соединений также, как и наличие кольца A- ими B-типа [7]. В фмаванонах цикл В не сопряжен с карбонильной группой, поэтому они обнаруживают наиболее симьное погмощение в области 270-290 nm (полоса II), тогда как полоса I образует уступ некоторой интенсивности при 320-330 nm. Спектры погмощения кумаринов содержат Аве главных полосы при 278 и $310 \mathrm{~nm}$, а у их гидроксимьных производных главный максимум расположен выше $300 \mathrm{~nm}$ [8].

Целью настоящей работы является установление закономерностей поглощения световой энергии в УФ-области Алин волн виноградными винами в зависимости от их типа и возраста, а так же массовой концентрации фенольных веществ. 


\section{Объекты и методы исследований}

В качестве материала Аля исследования были использованы столовые белые, столовые красные и белые керные вина различных годов урожая (2004-2018 гг.) всего 42 образца. Массовую концентрацию фенольных веществ проводили колориметрическим методом с помощью фотоэлектроколориметра КФК-ЗМ с реактивом Фолина-Чокальтеу по методике, приведенной в [9, С.93]. Аля регистрации спектров погмощения и измерения абсолютного значения оптической плотности опытных вин в УФ-области использовали оАнолучевой сканирующий спектрофотометр Specord 40 Analytik Jena c рабочим диапазоном Алин волн 190-1100 nm.

Методика исследований была слеАующей. Изначально в винах опредемяли массовую концентрацию фенольных веществ. Затем исследуемые образцы разводили дистилмированной водой в 15,30 и 60 раз и снимали спектры погмощения в области $220-430 \mathrm{~nm}$ в кварцевых кюветах с Алиной оптического пути 1 см. Разбавление выбира$\Lambda и$ из соображений, чтобы оптическая плотность образца не превышала 3-х. Оптиманьное значение оптической пмотности, обеспечивающее наибольшую точность ее измерения 0,30,7 единиц [10, С. 63]. В качестве раствора сравнения и Аля разбавления образцов вин использовали Аистимлированную воду, так как ввиду наличия буферных свойств у вин $\mathrm{pH}$ раствор образцов вин практически не изменяется.

\section{Результаты исследований и их} обсуждение

В результате анализа экспериментальных данных было установлено, что наиболее характерными Аля исследованных вин явцяется пик поглощения в области 265-285 nm, положение и форма которого зависит от их экстрактивности и возраста. Характерные формы кривых погмощения Амя разцичных типов вин приведены на рис. 1.

Анализ кривых погмощения показац, что при увеличении экстрактивности и возраста вина положение максимума пика поглощения в этой области Алин волн смещается в бомее Алинноволновую область. ОпреАеленные экспериментально среднее значения максимума поглощения Аця вин разАичных типов и возраста, а

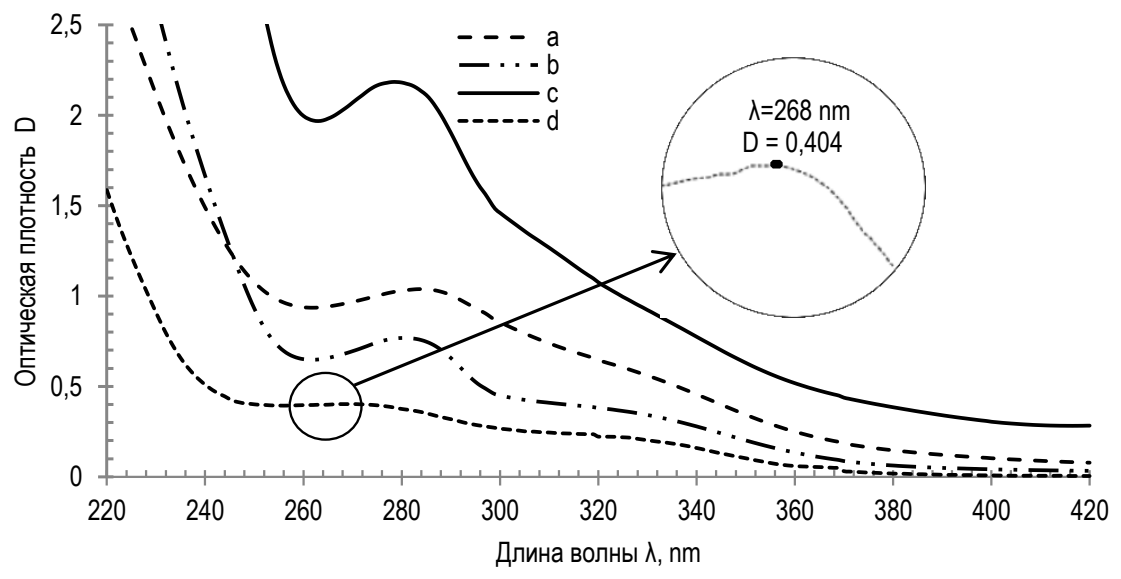

Рис. 1. Спектры поглощения различных типов вин (разбавление в 15 раз): а выдержанного крепленого, b - молодого крепленого, c - молодого столового красного, d - столового белого

Fig. 1. Absorption spectra of different types of wines (diluted 15 times): a - aged fortified, $\mathrm{b}$ - young fortified, $\mathrm{c}$ - young table red, $\mathrm{d}$ - table white

также 95\% Аоверительный интервац Аля этой величины приведены в таблице 1.

Выявлена также зависимость межАу возрастом вина и формой кривой оптической пмотности: форма пика становится менее выраженной и возрастает оптическая пмотность в области Алин волн свыше $300 \mathrm{~nm}$.

Установлена высокая степень корремяции меЖАУ оПтической пцотностью на Алине волны $(280 \pm 2) \mathrm{nm}$ и массовой концентрацией суммы фенольных веществ Аля вин разАичных типов,
Таблица 1. Положение максимума поглощения в области 265-285 nm для вин различных типов и возраста

Table 1. The maximum absorption position in the range of $265-285 \mathrm{~nm}$ for wines of various types and ages

\begin{tabular}{|c|c|c|}
\hline Тип вина & $\begin{array}{l}\text { Возраст вина, } \\
\text { годы }\end{array}$ & $\begin{array}{l}\text { Максимум, } \\
\mathrm{nm}\end{array}$ \\
\hline Столовое белое & AO 1 & $267 \pm 2$ \\
\hline Столовое белое & свыше 2 & $269 \pm 2$ \\
\hline Столовое красное & AO 1 & $277 \pm 2$ \\
\hline Столовое красное & $2-3$ & $280 \pm 2$ \\
\hline Аикерное белое & $1-2$ & $278 \pm 2,5$ \\
\hline Аикерное бемое & $3-7$ & $282 \pm 2,5$ \\
\hline Иикерное бемое & $8-10$ & $285 \pm 2,5$ \\
\hline
\end{tabular}
сгруппированных по возрасту. Аанные зависимости Аля молодых вин и выдержанных в течение 8-10 мет показаны на рис. 2.

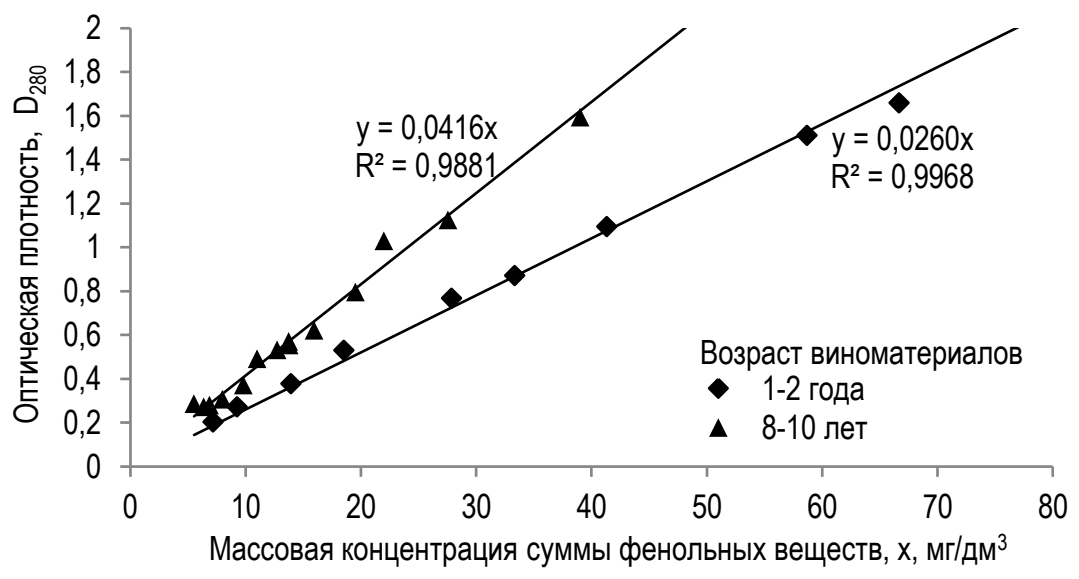

Рис. 2. Зависимость оптической плотности $D_{280}$ водных растворов вин различного возраста от концентрации суммы фенольных веществ (разбавление В 30 pa3)

Fig. 2. Correletion between optical density $D_{280}$ of aqueous solutions of wines of various ages and concentration of the sum of phenolic substances (diluted 30 times) 
Как видно из представленных на рис. 2 данных, интенсивность погмощения на Алине волны $280 \mathrm{~nm}$ Аля вин оАного возраста пропорционацьна массовой концентрации суммы фенольных веществ, опредеменной с реактивом Фолина-Чокальтеу. Несмотря на то, что форма пика максимума погмощения вина с выдержкой становится менее выраженной, величина абсорбции световой энергии на Алине волны 280 $\mathrm{nm}$, приходящаяся на единицу массы фенольных соеАинений, возрастает, что выражается в большем угле накмона кривой оптическая пмотность/массовая концентрация фенольных веществ. Это может быть объяснено разным качественным составом фенольных соединений молодых и выдержанных вин, и тем, что, несмотря на деградацию красителей и уменьшения общей концентрации фенольных соеАинений при выАержке, в системе остаются фенольные соединения винограда и их производные, определяемые с реактивом Фолина-Чокальтеу, интенсивно поглощающие в

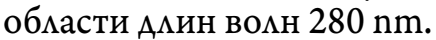

Это наталкивает на Ава направцения использования этого показателя Аця опредемения:

- массовой концентрации фенольных веществ в молодых виноматериалах;

- химического возраста виноматериала (по углу накмона кривой (концентрация - оптическая пмотность).

Аля абсолютных измерений светопоглощающей способности фенольных веществ целесообразно ввести понятие «коэффициент погмощения фенольных веществ винограда и вина». В аналитической химии обычно применяют понятие момярного коэффициента погмощения (погашения), который равен оптической плотности раствора с концентрацией $1 \mathrm{M} \mathrm{в} \mathrm{кювете} \mathrm{с} \mathrm{А \Lambda иной} \mathrm{оптического} \mathrm{пути}$ 1 см [10]. Ввиду того, что фенольные вещества винограда представлены смесью различных веществ фенольной природы разАичной степени полимеризации, то в качестве коэффициента поглощения фенольных веществ винограда целесообразно ввести оптическую плотность раствора на Алине волны $280 \mathrm{~nm}$ концентрации $1 \mathrm{r} / \mathrm{AM}^{3}$ фенольных веществ, определенной аттестованным методом с реактивом Фолина-Чокальтеу, при Алине оптического пути 1 см. Измерение этого показателя фенольных веществ виноматериалов следует проводить в области значений оптической плотности близкой к 0,434 путем разбавмения образца Аистимлированной водой.

Полученную величину оптической плотности потом следует умножить на разбавление вина и раздекить на массовую концентрацию фенольных веществ. Вычисленные величины коэффициента поглощения фенольных веществ винограда, полученные на основании статистической обработки спектрофотометрических данных по молодым виноматериалам, при 5\%-ном уровне значимости приведены в таблице 2 . Физический смысл этой величины - это оптическая пмотность раствора массовой концентрации феноцьных веществ 1 г/Ам ${ }^{3}$, определенных с реактивом Фомина-Чокальтеу по методике [9, С.93], при Алине оптического пути 1 см на Алине волны $280 \mathrm{~nm}$.
В этом случае, исходя из определения, концентрация фенольных веществ, в исследуемом образце будет равна

$$
\mathrm{C}=\frac{\mathrm{D}_{280} \times \mathrm{n}}{\varepsilon_{280}} \times 1000 \mathrm{M \Gamma} / \mathrm{AM}^{3},
$$

где $\mathrm{D}_{280}$ - оптическая плотность раствора виноматериала, измеренная на Алине волны $280 \mathrm{~nm}$ в кварцевой кювете с Алиной оптического пути $1 \mathrm{~cm}, \mathrm{n}-$ кратность разбав ения виноматериала, $\varepsilon_{280}-$ коэффициент поглощения фенольных веществ винограда (табл. 2), 1000 - коэффициент пересчета ААя получения Аанных B $\mathrm{M \Gamma} / \mathrm{AM}^{3}$.

Таблица 2. Коэффициент поглощения фенольных веществ винограда

Table 2. The phenolic substances absorption coefficient of grapes

\begin{tabular}{|c|c|c|}
\hline Тип вина & Возраст вина,, ет & $\varepsilon_{280}$ \\
\hline Белое столовое & $1-2$ & $26,1 \pm 1,5$ \\
\hline Красное столовое & $1-2$ & $23,0 \pm 2,0$ \\
\hline Белое микерное & $1-2$ & $26,0 \pm 0,7$ \\
\hline Бемое микерное & $8-10$ & $41,6 \pm 4,5$ \\
\hline
\end{tabular}

Рассмотрим теперь возможность непосредственного измерения оптической пмотности вин без их предварительного разбавления в контексте возможности созАания Аатчика ААя измерения оптической плотности в продуктах переработки винограда на Алине волны 275-280 $\mathrm{nm}$ с целью контроля массовой концентрации фенольных веществ винограда и вина. Учитывая, что максимацьная точность спектрофотометрических измерений достигается при значениях оптической пмотности 0,3-0,7 еА. и максимацьное значение измеряемой величины оптической плотности не Аолжно превышать 3 еА., что соответствует ослаблению интенсивности изцучения в 1000 раз, а концентрация фенольных веществ винограАа в основной массе измерений варьирует от $200 \mathrm{M \Gamma} / \mathrm{AM}^{3}$ Ао $1500 \mathrm{Mг} /$ $\mathrm{AM}^{3}$, то в Аатчике, регистрирующем оптическую плот-

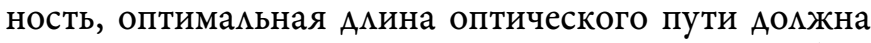
составцять 0,05 мм $\div 0,07$ мм, что эквивалентно разбавмению пробы в 15-20 раз.

Выводы. Таким образом, установмено, что кривая поглощения всех типов исследованных вин имеет мокальный максимум поглощения в Аиапазоне Алин волн 265-285 nm. При увеличении экстрактивности и возраста вин положение максимума пика поглощения

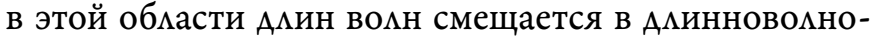
вую область.

Выявлена высокая степень коррецяции межАу оптической плотностью на Алине волны $280 \pm 2 \mathrm{~nm}$ и мас-

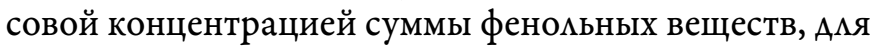
Аикерных и красных столовых вин, сгруппированных по возрасту.

Введено понятие «коэффициент поглощения фенольных веществ винограда и вина» - определены Аиапазон и численные значения этого коэффициента 


\section{ВИНОДЕЛИЕ}

Изучение спектров поглощения вин разАичных типов и возраста в УФ-диапазоне Алин волн

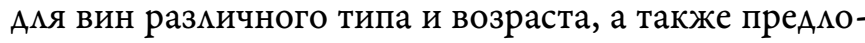
жен метод количественного опреАеления массовой концентрации фенольных веществ винограда и вина на основе испо ьзования этого коэффициента.

Определены оптимальные условия проведения спектрофотометрического опреАеления массовой концентрации суммы фенольных веществ (Алина вол-

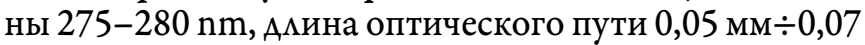
мм) без предварительного разбавления пробы в контексте возможного созАания спектрофотометрического Аатчика погружного типа ААя применения его ААя производственного контроця.

\section{Источник финансирования}

Не указан.

\section{Financing source}

Not specified.

\section{Конфликт интересов}

Не заяв ен.

\section{Conflict of interests}

Not declared.

\section{Список литературы / References}

1. Москвин А.Л., Ардашникова И.А., Тихомиров А.Б. Аппаратнопрограммный комплекс автоматизированных многопараметрических систем контроля водных сред / Научное приборостроение. - 2001. - T.2. - №2. - C. 70-77.

MoskvinA.L.,ArdashnikovaI.A., TihomirovA.B.Apparatno-programmnyj kompleks avtomatizirovanny mnogoparametricheskih sistem kontrolya vodnyb sred [Hardware-software complex of automated multiparameter control systems for aquatic environments]/Nauchnoe priborostroenie. [Scientific Instrumentation] - 2001. - V. 2. - №.2. - pp. 70-77. (in Russian)

2. Разаренова К.Н., Жохова Е.В. Сравнительная оценка содержания дубильных веществ в некоторых видах рода Geranium L. флоры северо-запада. - Химия растительного сырья. - 2011. - №4. - С. 187-192.

Razarenova K.N., Zhohova E.V. Sraunitel'naya ocenka soderzbaniya dubil'nyb veshchestv $v$ nekotoryb vidah roda Geranium L. flory severo-zapada [Comparative assessment of tannins in some species of the genus Geranium L. north-west flora.] - Himiya rastitel'nogo syr'ya [Chemistry of plant materials]. - 2011. - №4. - pp. 187-192. (in Russian)

3. Perkampus H.H. UV-VIS Spektroskopie und ihre Anwendungen/ Springer, Berlin. -1986.

\section{Тимофеев Р.Г.,}

Фоменко Н.А.

4. Сильверстейн Р., Басслер Г., Морил Т. Спектрометрическая идентификация органических соединений. М.: Мир. - 1977. - 590 с.

Silverstein R., Bassler G., Moril T. Spektrometricheskaya identifikaciya organicheskih soedinenij [Spectrometric identification of organic compounds]. Moscow: Mir. - 1977. - 590 p. (in Russian)

5. Пентин Ю.А., Вилков Л.В. Физические методы исследования в химии. М.: Мир, 2003. - 683 с., ил. - (Методы в химии).

Pentin Yu.A., Vilkov L.V. Fizicheskie metody issledovaniya $v$ bimii [Physical research methods in chemistry]. Moscow: Mir. - 2003. 683 p. (in Russian)

6. Свердлова О.В. Электронные спектры в органической химии. Л.: Химия. $-1985 .-248$ c.

Sverdlova O.V. Elektronnye spektry v organicheskoj bimii [Electronic spectra in organic chemistry]. Leningrad.: Chemistry, 1985. - 248 p. (in Russian)

7. Шкарина Е.И., Максимова Т.В., Никулина И.Н., Лозовская Е.П., Чумакова 3.В., Пахомов В.П., Сапежинский И.М., Арзамасцев А.П. О влиянии биологически активных веществ на антиоксидантную активность фитопрепаратов / Химико-фрармацевтический журнал. - 2001. - Т. 35. - № 6. - С. 41-47.

Shkarina E.I., Maksimova T.V., Nikulina I.N., Lozovskava E.P., Chumakova Z.V., Pakhomov V.P., Sapezhinsky I.M., Arzamastsev A.P. / O vliyanii biologicheski aktionyh veshchestv na antioksidantmuyu aktionost' fitopreparatov [On the effect of biologically active substances on the antioxidant activity of phytopreparations] / Himiko-farmacevticheskij zhurnal [Chemical-Pharmaceutical Journal]. - 2001. - Vol. 35. - №6. - pp. 41-47. (in Russian)

8. Блажей А., Шутый Л. Фенольные соединения растительного происхождения / Пер. со словацкого. М.: Мир, 1977.

Blazhey A. Fenol'nye soedineniya rastitel'nogo proiskbozbdeniya [Phenolic compounds of plant origin] / A. Blazhey, L. Shutyi // translation from Slovak. Ed. Moscow: Mir. - 1977. (in Russian)

9. Методы технохимического и микробиологического контроля в виноделии / [Под ред. Гержиковой В. Г.]. - Симферополь: Таврида. $-2002 .-259$ c.

Metody tekbnobimicheskogo $i$ mikrobiologicheskogo kontrolya $v$ vinodelii [Methods of techno-chemical and microbiological control in winemaking] / [Ed. Gerzhikova V.G.]. - Simferopol: Tavrida. - 2002. -259 p. (in Russian)

10. Булатов М.И., Калинкин И.П. Практическое руководство по фотоколориметрическим и спектрофотометрическим методам анализа /Изд. 2-е, перераб. и доп. - Л.: Химия, 1968. - 384 с.

Bulatov M.I., Kalinkin I.P. Prakticheskoe rukovodstvo po fotokolorimetricheskim ispektrofotometricheskim metodam analiza [A practical guide to photocolorimetric and spectrophotometric methods of analysis] Ed. 2nd, revised and add. - Leningrad, Chemistry. - 1968. - 384 p. (in Russian) 